\title{
The short and long term effects of exercise training in non-cystic fibrosis bronchiectasis - a randomised controlled trial
}

\author{
Annemarie L Lee ${ }^{1,2,3^{*}}$, Catherine J Hill ${ }^{2,4}$, Nola Cecins ${ }^{5,6}$, Sue Jenkins ${ }^{5,6,7}$, Christine F McDonald ${ }^{2,4}$, Angela T Burge ${ }^{1}$, \\ Linda Rautela ${ }^{2,4}$, Robert G Stirling ${ }^{1,8}$, Philip J Thompson ${ }^{5,6,7}$ and Anne E Holland ${ }^{1,2,9}$
}

\begin{abstract}
Background: Exercise training is recommended for non-cystic fibrosis (CF) bronchiectasis, but the long-term effects are unclear. This randomised controlled trial aimed to determine the effects of exercise training and review of airway clearance therapy (ACT) on exercise capacity, health related quality of life (HRQOL) and the incidence of acute exacerbations in people with non-CF bronchiectasis.

Methods: Participants were randomly allocated to 8 weeks of supervised exercise training and review of ACT, or control. Primary outcomes of exercise capacity and HRQOL (Chronic respiratory disease questionnaire) and secondary outcomes of cough-related QOL (Leicester cough questionnaire) and psychological symptoms (Hospital anxiety and depression scale) were measured at baseline, following completion of the intervention period and at 6 and 12 months follow up. Secondary outcomes of the exacerbation rate and time to first exacerbation were analysed over 12 months.

Results: Eighty-five participants (mean FEV $174 \%$ predicted; median Modified Medical Research Council Dyspnoea grade of 1 (IQR [1-3]) were included. Exercise training increased the incremental shuttle walk distance (mean difference to control $62 \mathrm{~m}, 95 \% \mathrm{Cl} 24$ to $101 \mathrm{~m}$ ) and the 6-minute walking distance (mean difference to control $41 \mathrm{~m}, 95 \% \mathrm{Cl}$ 19 to $63 \mathrm{~m}$ ), but these improvements were not sustained at 6 or 12 months. Exercise training reduced dyspnoea $(p=0.009)$ and fatigue $(p=0.01)$ but did not impact on cough-related $Q O L$ or mood. Exercise training reduced the frequency of acute exacerbations (median 1[IQR 1-3]) compared to the control group (2[1-3]) over 12 months follow up ( $p=0.012$ ), with a longer time to first exacerbation with exercise training of 8 months ( $95 \% \mathrm{Cl} 7$ to 9 months) compared to the control group (6 months [95\% Cl 5 to 7 months], $p=0.047$ ).
\end{abstract}

Conclusions: Exercise training in bronchiectasis is associated with short term improvement in exercise capacity, dyspnoea and fatigue and fewer exacerbations over 12 months.

Trial registry: ClinicalTrials.gov (NCT00885521).

Keywords: Bronchiectasis, Exercise training, Quality of life, Exercise capacity, Acute exacerbations

\section{Introduction}

Bronchiectasis unrelated to cystic fibrosis (non-CF bronchiectasis) is a chronic respiratory condition characterised by bronchial dilatation secondary to airway inflammation, infection and dysfunction of mucociliary clearance [1]. Common features include persistent cough with chronic sputum production, dyspnoea and fatigue $[2,3]$. This

\footnotetext{
* Correspondence: Annemarie.Lee@alfred.org.au

${ }^{1}$ Alfred Health, Commercial Road, Melbourne 3004, Victoria, Australia ${ }^{2}$ Institute for Breathing and Sleep, 145 Studley Road, Heidelberg 3084, Australia Full list of author information is available at the end of the article
}

clinical profile is associated with increased anxiety and depression, reduced health-related quality of life (HRQOL) and impaired exercise tolerance [3,4]. Patients with non-CF bronchiectasis frequently experience acute exacerbations [5], which are an independent predictor of progressive decline in respiratory function and a poorer prognosis [6,7]. While the global prevalence of non-CF bronchiectasis is unknown, it is associated with rising hospitalisation rates amongst the older population [8-10]. This growing healthcare utilisation and economic burden [11,12] emphasises 
the need for effective medical and physiotherapy treatment approaches.

Current guidelines for the treatment of non-CF bronchiectasis recommend pulmonary rehabilitation, with the aim of improving exercise tolerance and HRQOL [13]. Pulmonary rehabilitation often incorporates self-management strategies to promote treatment adherence and this approach has been advocated for bronchiectasis [14]. There is limited evidence of the effects of pulmonary rehabilitation in non-CF bronchiectasis, with two retrospective studies demonstrating similar benefits in exercise capacity and HRQOL as those observed in patients with chronic obstructive pulmonary disease (COPD) [15,16]. Two prospective studies showed short-term improvements in exercise capacity and HRQOL with a combination of endurance, strength training and inspiratory muscle training [17] or regular airway clearance therapy (ACT) [18]. These studies incorporated formal education as part of the clinical approach and had a follow up period of three months; it is not clear if benefits persist in the longer term.

Health benefits are also assessed through qualityadjusted life years (QALYs), which quantify the benefit gained from an intervention by measuring the change in HRQOL over time. In COPD, pulmonary rehabilitation (exercise training and education) has been associated with fewer acute exacerbations and improved QALYs [19]. Whether similar effects are achieved in bronchiectasis is unknown.

Therefore, the aims of this study were to 1) determine the short and long-term effects of exercise training and review of ACT on exercise capacity and dimensions of HRQOL and 2) evaluate the effect of this intervention on the incidence of acute exacerbations over a 12-month follow up period.

\section{Methods \\ Participants}

A multi-site, randomised, single blinded, controlled trial was conducted at three tertiary teaching hospitals, the Alfred and Austin Hospitals (Victoria) and Sir Charles Gairdner Hospital (Western Australia), Australia. Adults aged over 18 years with non-CF bronchiectasis, confirmed on high resolution computed tomography (HRCT), were invited to participate. The detailed methodology of this study has been published previously [20].

Patients were eligible to participate if they were ambulant and reported dyspnoea on exertion (Modified Medical Research Council (MMRC) Dyspnoea grade $\geq 1$ ) [21], clinically stable and self-reported at least two exacerbations requiring antibiotics per year within the previous two years. Exclusion criteria were other concurrent respiratory diseases, including COPD (smoking history of greater than 10 pack years and evidence of emphysema on HRCT) [22], interstitial lung disease (ILD) or asthma (clinical diagnosis and reversibility $>12 \%$ ) [23], comorbidities which precluded safety to undertake exercise training or participation in pulmonary rehabilitation in the previous 12 months. The study was approved by the Human Research Ethics Committees at all trial sites with written informed consent obtained from all participants. The trial was registered with ClinicalTrials.gov (NCT00885521).

After stratification for sputum quantity (small volume: $\leq$ one tablespoon per day, large volume: > one tablespoon per day), which was based on classifications previously described [2] and is associated with decline in $\mathrm{FEV}_{1}$ [7], participants were randomised to the intervention or control group at a central location using a computergenerated randomisation sequence, which was concealed using sealed, opaque envelopes and prepared by an independent individual. Baseline measurements of spirometry were obtained and repeated immediately following the intervention period and at follow up. Prior to randomisation, all participants received instruction and review of their usual ACT, with instructions standardised across sites. Any participant who had no prior instruction in ACT was taught the active cycle of breathing technique [24] while those with established ACT had their technique reviewed and corrected if necessary. All participants, irrespective of group allocation, were encouraged to continue with their ACT for the study duration.

\section{Intervention}

The intervention group attended a twice-weekly exercise program for eight weeks at the institution in which they were recruited. Exercise training consisted of an individually prescribed exercise program and included treadmill or land based walking, with the initial intensity set to $75 \%$ of the maximal speed achieved on the incremental shuttle walk test (ISWT) [25,26], stationary cycling prescribed at $60 \%$ of maximal work-rate for cycling [27] and upper and lower limb strength training using free weights and/or body weight $[25,26]$. Exercises were progressed each session according to patient symptom ratings (modified Borg scale for dyspnoea and perceived exertion), similar to COPD training principles $[25,26]$. Attendance of at least 12 out of 16 exercise sessions was considered completion of the exercise intervention [28]. Following the establishment of a safe exercise regimen, a home exercise program was prescribed in week one, with the aim of achieving three to five unsupervised sessions per week with sessions recorded in an exercise diary. Participants were instructed to maintain this routine during the follow up period and were reminded via monthly telephone calls over the follow up period. To encourage adherence to ACT, an average rating of sputum volume using a visual analogue scale (VAS) was recorded weekly. If necessary, ACT was reviewed and corrected. 
The control group did not receive supervised exercise training but were informed at baseline that undertaking 30 minutes of moderate intensity physical activity most days of the week was associated with health benefits [29]. During the eight week intervention, participants were contacted by telephone twice-weekly, to provide support and general advice with no discussion of exercise or physical activity. The control group did not complete an average sputum rating and did not have an opportunity for their ACT to be reviewed or corrected.

\section{Outcome measures}

Over two days of assessment at each time point, primary and secondary outcomes were measured at baseline, immediately following the intervention (nine weeks) and at six and 12 months post intervention by an assessor blinded to group allocation. One site did not participate in the long term follow up due to ethical concerns relating to denial of exercise training to the control group for 12 months. The primary outcome of maximal exercise capacity was the incremental shuttle walk distance (ISWD), with the ISWT performed to a standardised protocol [30]. Two tests were completed at each assessment, with the maximal distance of two tests recorded [30]. The self-reported version of the Chronic respiratory disease questionnaire (CRDQ) was used to measure HRQOL [31]. This has been previously used to assess HRQOL in patients with bronchiectasis [15].

Secondary outcomes included functional exercise capacity, measured with the 6-minute walk test (6MWT). Two tests were completed on each assessment occasion to a standardised protocol, with the maximal 6-minute walk distance (6MWD) of the two tests recorded [32]. The Leicester cough questionnaire (LCQ) was applied to measure the physical, psychological and social impact of chronic cough [33] and the Hospital anxiety and depression scale (HADS) measured psychological symptoms of anxiety and depression [34].

To determine an individual's utility of health status at a specific point in time, the Assessment of Quality of Life (AQOL) was applied [35]. The AQOL has five dimensions including illness, independent living, social relationships, physical senses and psychological well-being, with item responses based on four point ordinal scales. The AQOL was converted into a value index using preference weights derived from Australian population samples, which were combined into a single score of the utility index [35]. The highest score of 1 represents perfect health, 0 represents death and negative values (i.e. -0.04) represent a state of worse than death. The health state was then multiplied by the time spent in that state (one year in this study) to derive the QALYs gained or lost following an intervention $[19,35]$.
During the eight week intervention period and over the 12 month follow up, all participants maintained a daily diary recording changes in symptoms. This symptom record was used to identify an exacerbation, which was defined as the presence of $\geq$ four signs and symptoms (including change in sputum amount, thickness or colour, haemoptysis, increased cough, tiredness, shortness of breath or fever $>38$ degrees Celcius) [5] for two or more consecutive days with and without prescription of new antibiotics. To ensure adherence to diary completion, participants in both groups were contacted by telephone monthly over the follow up period. Exacerbation data were extrapolated from diary records by an independent assessor blinded to group allocation, which was then verified with the participant's general practitioner or hospital records.

\section{Statistical analysis}

For the primary outcomes, for an $80 \%$ probability of detecting a difference in ISWD, a total of 36 participants were required, based on the assumption of a difference between groups of $55 \mathrm{~m}$, with a standard deviation (SD) of $74 \mathrm{~m}$ [3]. For an $80 \%$ probability of detecting a difference in HRQOL, 44 subjects were required. This was based on the assumption that a difference between groups is 5.4 units for the CRDQ emotional function domain, with a SD of 6.3 units using an unstandardised scale, according to pilot data collected on 33 patients at one recruiting centre. For the secondary outcomes, for an $80 \%$ probability of detecting a difference in number of exacerbations, 64 participants were required, based on the assumption that a difference between groups was 1.0 exacerbation, with a SD of 1.4 exacerbations [7]. To account for $20 \%$ attrition, a total of 85 subjects were recruited.

Data analysis was completed based on intention-totreat principles, in which all participants were scheduled to attend follow up assessment, irrespective of completion and all available data from participants attending these assessment (Figure 1) has been included in the analysis [36]. Missing data were replaced by the last observation carried forward method (LOCF), with the robustness of this analysis checked with a sensitivity analysis in which the observed means from the exercise and control groups were substituted for missing data in the opposite arm [37]. The sensitivity analysis confirmed the results of the primary endpoint and hence LOCF analyses have been reported. Data were expressed as mean and standard deviation (SD) or median and interquartile range (IQR). Analysis was completed using two way analysis of variance to account for group and time interaction. Non parametric data were compared between groups using the Mann Whitney $U$ test. Time to first exacerbation was assessed via Kaplan-Meier survival analysis using log-rank tests to compare groups. Analyses were performed 


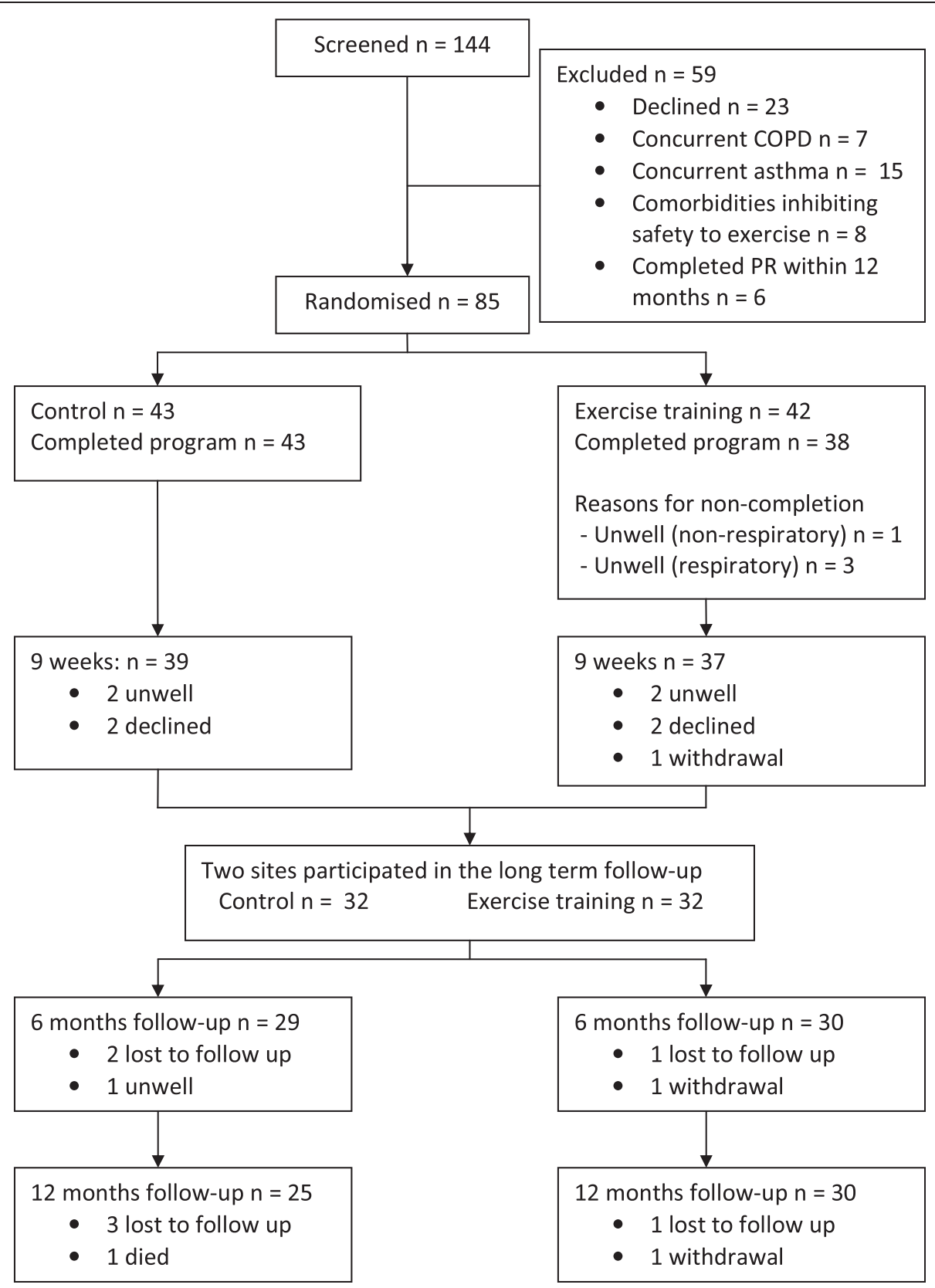

Figure 1 Flow of participants.

using the Statistical Package for Social Sciences (SPSS version 17.0; Chicago, IL, USA) with $\mathrm{p}<0.05$ used to denote statistical significance.

\section{Results}

Between April 2009 and February 2011, a total of 144 patients were screened (Figure 1), 36 were excluded prior to randomisation for not meeting the inclusion criteria and a further 23 declined to participate. The subject flow reflected the recommendations from the Consolidated Standards of Reporting Trials (CONSORT) statement [38].
A total of 42 were randomised to the exercise training group and 43 to the control group. All participants had been previously prescribed ACT. For those in the intervention group, no changes to $\mathrm{ACT}$ regimens were required by any participant over the eight week duration and the average VAS sputum volume rating did not change over the intervention period $(\mathrm{p}=0.56)$. Adherence to exercise diary completion during the 8 week program in the exercise group was $29 \%$. All control group participants reported no change to their usual exercise patterns between baseline assessment and at 9 weeks follow up. 
One participant in the exercise group withdrew from the study during the intervention phase due to an illness unrelated to bronchiectasis. Data for this participant were not available at nine weeks, six or 12 months. There was one death in the control group from respiratory failure. A total of 38 (90\%) participants completed the exercise training, with reasons for non-completion outlined in Figure 1. Reasons for not undertaking outcome measures at the nine week assessment were respiratory illness $(n=3)$, fractured thoracic spine which was unrelated to exercise training $(n=1)$ or declined to attend $(n=4)$. Baseline characteristics of the 85 participants are shown in Table 1, with no difference between groups at baseline in any measures. According to the MMRC Dyspnoea grade, the extent of functional impairment in exercise capacity was mild with 64 (75\%) participants reporting dyspnoea only on strenuous activity (MMRC Grade 1). There was no change in $\mathrm{FEV}_{1}(\mathrm{p}=0.26)$ or $\mathrm{FVC} \%$ predicted $(\mathrm{p}=0.43)$ over the study duration in either group.

The effect of exercise training on maximal exercise capacity is shown in Figure 2. There was a significant interaction between group and time for ISWD ( $\mathrm{p}=0.005)$. The ISWD improved in the exercise group following training, with a mean difference $(95 \% \mathrm{CI})$ of $62 \mathrm{~m}(24$ to $101 \mathrm{~m}$ ) compared to the control group. However, this improvement was not sustained at either six or 12 months. For the CRDQ, the exercise group demonstrated a

Table 1 Baseline demographics of participants

\begin{tabular}{lrr}
\hline & $\begin{array}{r}\text { Control } \\
\mathbf{n}=\mathbf{4 3}\end{array}$ & $\begin{array}{r}\text { Exercise } \\
\mathbf{n}=\mathbf{4 2}\end{array}$ \\
\hline Gender: Male/Female & $12 / 31$ & $12 / 30$ \\
Age (years) & $65(12)$ & $63(13)$ \\
BMI $\left(\mathrm{kg} / \mathrm{m}^{2}\right)$ & $24.2(4.5)$ & $24.7(5.9)$ \\
FEV ${ }_{1} \%$ predicted & $77(18)$ & $70(23)$ \\
FVC\% predicted & $84(18)$ & $79(22)$ \\
FEV $/$ FVC & $80 .(14)$ & $82(12)$ \\
MMRC & $1.5(0.7)$ & $1.3(0.5)$ \\
6MWD (m) & $578(90)$ & $551(90)$ \\
6MWD\% predicted & $84(12)$ & $85(12)$ \\
ISWD (m) & $474(157)$ & $464(150)$ \\
ISWD\% predicted & $77(22)$ & $76(24)$ \\
Total CRDQ score & $91.0(18.6)$ & $88.9(16.1)$ \\
Total LCQ score & $14.5(3.6)$ & $15.1(3.1)$ \\
HADS Anxiety & $4.4(3.1)$ & $4.8(3.4)$ \\
HADS Depression & $3.5(2.8)$ & $3.1(2.9)$ \\
No of exacerbations in previous 2 years & $5.3[4.8]$ & $5.1[4.6]$ \\
\hline
\end{tabular}

Data are mean (SD) or median [IQR] unless otherwise stated. BMI - Body mass index; FEV 1 - Forced expiratory volume in 1 second; FVC - Forced vital capacity; MMRC - Modified Medical Research Council Dyspnoea Scale; 6MWD - 6-minute walk distance; ISWD - Incremental shuttle walk distance; CRDQ - Chronic Respiratory Disease Questionnaire; LCQ - Leicester Cough Questionnaire; HADS - Hospital Anxiety and Depression scale; No - number.

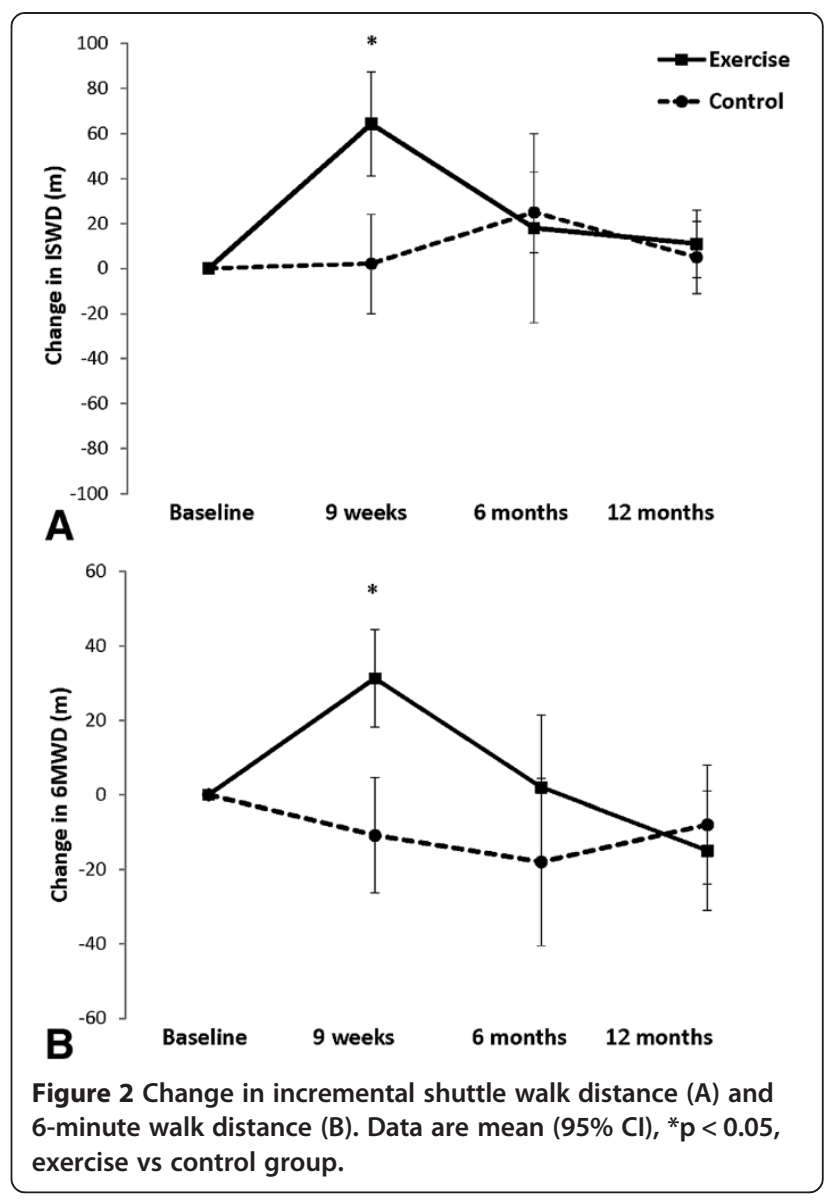

significant reduction in dyspnoea $(\mathrm{p}=0.009)$ and fatigue ( $\mathrm{p}=0.01$ ) compared to the control group immediately following training (Figure 3), but these improvements were not sustained when assessed at six and 12 months. There was no significant change in emotional function or mastery.

Of the secondary outcomes, there was a significant improvement in functional exercise tolerance following training, with a mean change $(95 \% \mathrm{CI})$ in 6MWD of $41 \mathrm{~m}$ (19 to $63 \mathrm{~m})$ compared to the control group, but this improvement was not sustained over the longer term. There were no significant differences between groups in any of the LCQ domains or in anxiety or depression immediately following intervention or at follow up (Table 2).

The adherence rate to symptom diary completion was $82 \%$ in the exercise group and $77 \%$ for the control group. A total of 12 participants in the exercise group and 18 in the control group experienced at least one exacerbation over the 12 months follow up. There was a longer median time to first exacerbation in the exercise group of 8 months (95\% CI 7 to 9 months), compared to control group of 6 months (5 to 7 months), with log rank of 0.49 (95\% CI 0.01 to 0.97), $\mathrm{p}=0.047$ (Figure 4). Exercise training reduced the number of exacerbations over 


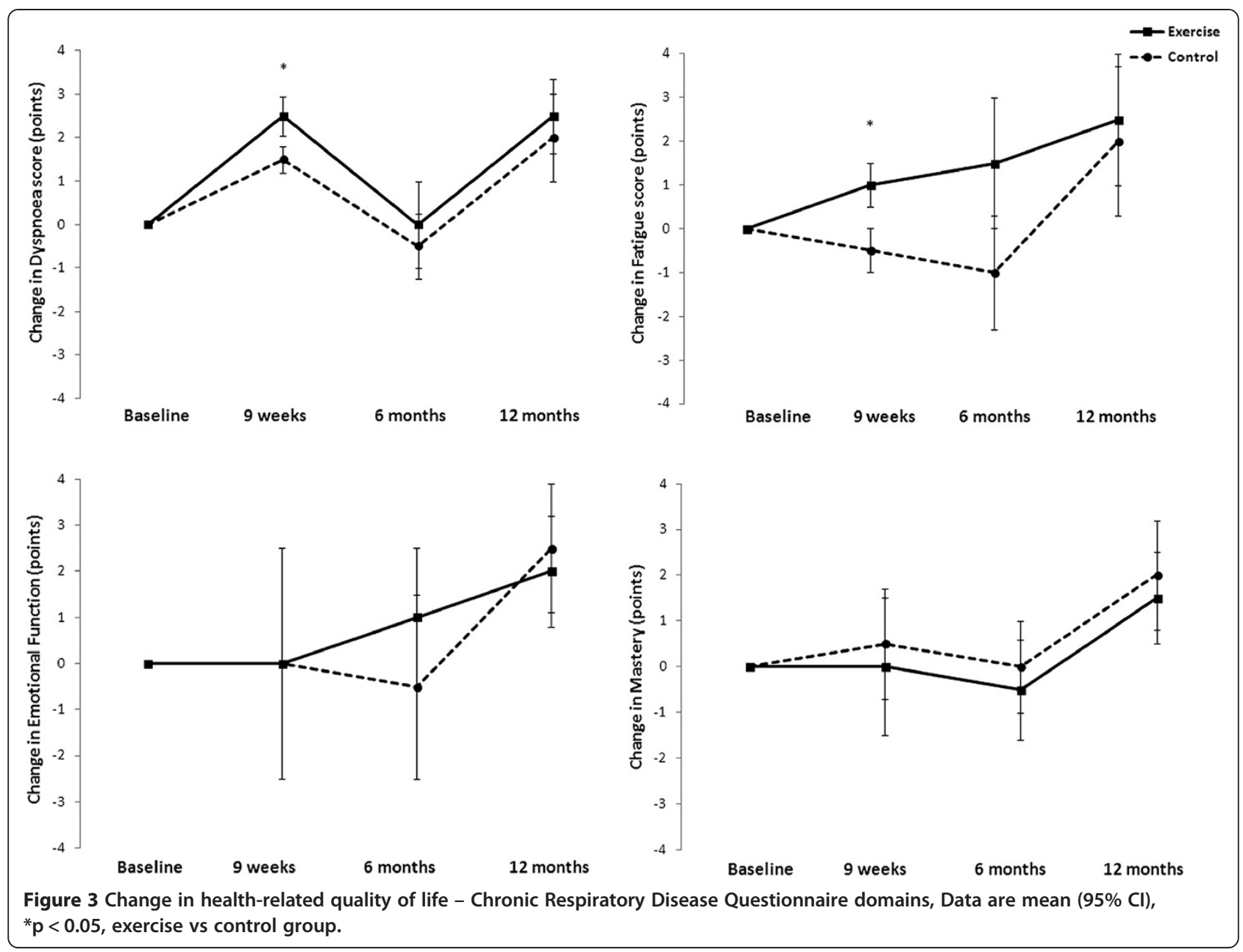

12 months (Table 3), with a trend towards fewer exacerbations requiring antibiotics $(\mathrm{p}=0.061)$. There was no significant difference between groups in the number of days or exacerbation days requiring antibiotics for each exacerbation. The relative risk of exacerbation was 0.69 ( $95 \%$ CI 0.49 to 0.98 ), indicating there was less risk of exacerbation in the exercise group compared to the control group.

The health utility scores of the AQOL before intervention (baseline) and 12 months following completion of intervention showed a mean (SD) gain in QALYs from 0.74 (0.22) to $0.88(0.17)$ in the exercise group and from $0.74(0.17)$ to $0.89(0.11)$ in the control group. While there was a significant gain in QALYs over 12 months within both groups (both $\mathrm{p}<0.001$ ), the mean difference of 0.004 ( $95 \%$ $\mathrm{CI}-0.08$ to 0.09 ) between groups was not significant.

\section{Discussion}

To date, this is the only trial of exercise training and regular review of ACT in non-CF bronchiectasis which incorporated 12 months follow up. We have demonstrated short term gains in exercise capacity as well as improvement in symptoms of dyspnoea and fatigue, but these benefits were not sustained beyond program completion. With exercise training, the time to first exacerbation was longer and the number of exacerbations over a 12 month period was reduced. There was no benefit in cough related QOL, change in levels of anxiety or depression or greater improvement in QALYs.

This is the first study to show a reduction in the number of acute exacerbations over the 12 months following exercise training and a longer time to first exacerbation. While the reduced exacerbation frequency in the exercise training group should be interpreted with caution, due to the proportion of participants who were unable to complete 12 months follow up, these findings are encouraging and are similar to case series reports [39]. The mechanism by which exercise training reduced exacerbation frequency is unclear. It could be argued that the review of ACT as necessary in the intervention group may account for the difference, but the familiarity of all participants with ACT prior to study enrolment, the lack of change in ACT regimen for the intervention group and the absence of reinforcement over the follow up suggests 
Table 2 Effect of exercise training on cough related quality of life and psychological symptoms

\begin{tabular}{|c|c|c|c|c|c|}
\hline & Baseline & 9 weeks & 6 months & 12 months & $p$ value \\
\hline \multicolumn{6}{|c|}{ LCQ Physical } \\
\hline Exercise & $5.0(1.0)$ & $5.3(0.9)$ & $4.7(1.4)$ & $4.8(1.7)$ & \\
\hline Control & $5.0(1.0)$ & $5.2(0.8)$ & $4.8(1.6)$ & $5.5(1.1)$ & 0.33 \\
\hline \multicolumn{6}{|c|}{ LCQ Psychological } \\
\hline Exercise & $4.9(1.8)$ & $5.5(1.3)$ & $5.2(1.7)$ & $5.6(1.2)$ & \\
\hline Control & $5.7(1.3)$ & $5.8(1.1)$ & $5.3(1.8)$ & $6.2(1.0)$ & 0.11 \\
\hline \multicolumn{6}{|l|}{ LCQ Social } \\
\hline Exercise & $5.3(2.7)$ & $4.6(1.0)$ & $5.5(2.2)$ & $3.1(2.5)$ & 0.98 \\
\hline Control & $4.8(1.1)$ & $4.5(0.9)$ & $5.3(1.9)$ & $6.2(1.2)$ & \\
\hline \multicolumn{6}{|l|}{ LCQ Total } \\
\hline Exercise & $15.2(3.4)$ & $15.4(2.1)$ & $15.4(1.6)$ & $13.5(3.1)$ & \\
\hline Control & $15.5(1.2)$ & $15.5(1.9)$ & $15.4(3.6)$ & $17.9(2.8)$ & 0.82 \\
\hline \multicolumn{6}{|c|}{ HADS Anxiety } \\
\hline Exercise & $4.8(3.4)$ & $4.6(3.7)$ & $3.7(2.9)$ & $3.1(2.5)$ & \\
\hline Control & $4.4(3.1)$ & $4.0(2.7)$ & $3.7(3.2)$ & $3.4(3.5)$ & 0.19 \\
\hline \multicolumn{6}{|c|}{ HADS Depression } \\
\hline Exercise & $3.1(2.9)$ & $3.5(3.4)$ & $2.7(2.7)$ & $2.7(2.7)$ & \\
\hline Control & $3.5(2.8)$ & $3.2(2.2)$ & $3.5(3.3)$ & $2.9(3.1)$ & 0.63 \\
\hline
\end{tabular}

Data are mean (SD), $\mathrm{p}$ value represents difference between groups.

LCQ - Leicester cough questionnaire; HADS - Hospital anxiety and depression scale.

this is unlikely. Improved immune function has been demonstrated with moderate intensity exercise in healthy elderly individuals [40]; a similar mechanism may be present in this study. In CF, the increase in expiratory flow and promotion of annular airflow during a single session of exercise has been associated with improved mucociliary clearance, although the long term effects are unknown [41]. We did not collect information related to bacterial colonisation, or other markers in inflammation in this study. Given the significant influence of distal airway colonisation upon exacerbation severity and decline in

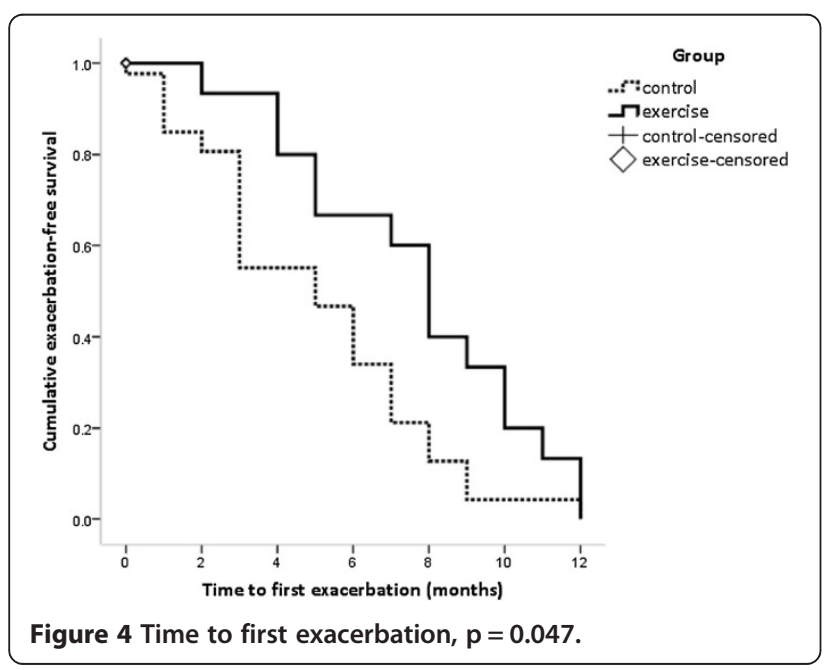

lung function $[7,42,43]$, further examination of the physiological effects of exercise training is needed.

The mean improvement of $64 \mathrm{~m}$ in the ISWD and $41 \mathrm{~m}$ in the 6WMD is consistent with retrospective findings in this patient population $[15,16]$ as well as those from a comprehensive pulmonary rehabilitation program complemented by ACT [18]. Although the magnitude of increase in ISWD was less in comparison to pulmonary rehabilitation with inspiratory muscle training [17], it suggests that exercise capacity improvement in bronchiectasis can be achieved using training principles similar to those applied in COPD $[14,26]$. While the level of functional impairment prior to intervention was mild compared to some studies [16,18], the MMRC grades and baseline walking tests were equivalent to other reports of patients included in pulmonary rehabilitation programs [17]. With this magnitude of improvement in patients with mild

Table 3 Number of exacerbations over 12 months $(n=55)$

\begin{tabular}{lrrr}
\hline & $\begin{array}{r}\text { Control } \\
\mathbf{n = 2 5}\end{array}$ & $\begin{array}{r}\text { Exercise } \\
\mathbf{n = 3 0}\end{array}$ & p value \\
\hline Exacerbations & $2(1-3)$ & $1(0-2)$ & 0.012 \\
Exacerbations requiring antibiotics & $2(0-4)$ & $1(0-2)$ & 0.061 \\
Exacerbation days & $10(2-13)$ & $7(3-11)$ & 0.23 \\
Exacerbation days with antibiotics & $11(2-15)$ & $7(2-13)$ & 0.36 \\
\hline Data are median (IQR), p value represents difference between groups.
\end{tabular}


disease severity and functional limitation, it may be that those with more severe disease and impairment could achieve even greater benefit from this intervention, but this requires further investigation. Our results suggest that the benefits appear to be independent of a comprehensive education program, which has been part of previous work $[15,17,18]$. While the extent of improvement in 6MWD is similar to the described minimal important difference in COPD [44], this has not yet been defined for bronchiectasis. Therefore the clinical significance of the improvements in exercise capacity requires confirmation.

While exercise training was not associated with a greater improvement in QALYs, in contrast to previous reports in COPD [19], the study was not powered for this outcome and the follow up time was short. Health utility is only one dimension of the cost effectiveness and cost utility of this treatment approach. Further exploration of the economic benefit of this intervention, including measures of cost per QALY $[19,35]$ in bronchiectasis is warranted.

The short-term duration of benefit following exercise training is a common finding in chronic respiratory conditions [14]. Despite monthly telephone follow up and instructions to complete an exercise diary beyond the intervention period, the adherence rate was poor and the absence of a structured exercise program may have impeded the ability to maintain initial improvements. While these results contrast with a retrospective report of pulmonary rehabilitation, which demonstrated that improvement was maintained at 12 months, these effects may have been overestimated, with a significant attrition rate $(>50 \%)$ in this previous study [15]. The functional decline over time reflects a similar pattern to that observed in COPD and ILD [14,28], despite reports of a slower rate of decline in lung function in bronchiectasis compared to these conditions [45-48]. We found that the 6MWD at 12 months was worse than baseline, suggesting that despite the mild disease evident in this sample, exercise capacity has the potential to decline further over time. Reports in COPD have demonstrated that immediately following pulmonary rehabilitation, an increase in physical activity is evident, but the magnitude is small, with suggestions that a longer duration of treatment is necessary to encourage behavioural change [49-51]. Our results suggest that sustained gains in symptoms and functional capacity may require longer interventions or maintenance programs for people with bronchiectasis.

This is the first prospective study to isolate improvement in dypsnoea and fatigue in people with non-CF bronchiectasis, both key symptoms which contribute to HRQOL $[2,3]$. The lack of change in psychological symptoms may be due to the few participants with clinically significant anxiety or depression at baseline. Similarly, the well preserved emotional function and mastery at study commencement in both groups, a contrast to COPD [14], may account for the lack of effect on these measures following exercise training. Finally, all participants had long-standing bronchiectasis and the possibility of a greater tolerance of cough-related symptoms, as reflected by the high baseline scores for the LCQ. These clinical factors combined with similar initial instruction in ACT and the consistent regimen during the study in both groups may account for the negligible effect of exercise training on cough-related QOL.

In conclusion, this study demonstrates that a supervised exercise program of eight weeks is associated with shortterm improvement in exercise capacity, dyspnoea and fatigue. Exercise training is associated with a reduction in the frequency of acute exacerbations of bronchiectasis over 12 months, however it appears to have minimal effect on cough related QOL. The significance of these findings for long-term prognosis requires further exploration.

\section{Abbreviations}

ACT: Airway clearance techniques; AQOL: Assessment of quality of life; CF: Cystic fibrosis; COPD: Chronic obstructive pulmonary disease;

CRDQ: Chronic respiratory disease questionnaire; FEV $\mathrm{F}_{1}$ : Forced expiratory volume in one second; FVC: Forced vital capacity; HADS: Hospital anxiety and depression scale; HRQOL: Health-related quality of life; HRCT: High resolution computed tomography; ILD: Interstitial lung disease;

IQR: Interquartile range; ISWD: Incremental shuttle walk distance; ISWT: Incremental shuttle walk test; LCQ: Leicester cough questionnaire; LOCF: Last observation carried forward; MMRC: Modified Medical Research Council; QOL: Quality of life; SD: Standard deviation; VAS: Visual analogue scale; 6MWD: 6-minute walk distance; 6MWT: 6-minute walk test.

\section{Competing interests}

The authors declare that they have no competing interests.

\section{Authors' contributions}

Conception and design: AL, CH, NC, SJ, CM, LR, PT, RS, AH. Acquisition of data: $A L, C H, N C, S J, A B$. Analysis and interpretation: $A L, C H, N C, S J, C M, A H$. Drafting the article for important intellectual content: $A L, C H, N C, S J, C M, A B$, $L R, P T, R S, A H$. All authors contributed to the intellectual content of the manuscript and were consulted for final approval of the submitted version.

\section{Acknowledgements}

This research was supported by The Alfred Foundation Research Trust, The Institute for Breathing and Sleep, the Sir Charles Gairdner Hospital Research Fund and the Alfred Physiotherapy Research Grant. The authors would like to acknowledge Caroline Nicolson for her assistance in data management, Holly Landers (blinded assessor), Nicole Stodden, intervention physiotherapist and Leona Dowman, exercise physiologist.

\section{Author details}

${ }^{1}$ Alfred Health, Commercial Road, Melbourne 3004, Victoria, Australia. ${ }^{2}$ Institute for Breathing and Sleep, 145 Studley Road, Heidelberg 3084, Australia. ${ }^{3}$ Physiotherapy, Melbourne School of Health Sciences, The University of Melbourne, 161 Barry Street, Carlton 3010, Australia. ${ }^{4}$ Austin Health, 145 Studley Road, Heidelberg 3084, Australia. ${ }^{5}$ Sir Charles Gairdner Hospital, Hospital Avenue, Nedlands, Perth 6009, Australia. ' ${ }^{6}$ ung Institute of Western Australia and Centre for Asthma, Hospital Avenue, Nedlands, Perth 6009, Australia. ${ }^{7}$ Curtin University, Kent Street, Bentley, Perth 6102, Australia. ${ }^{8}$ Department of Medicine, Monash University, Melbourne 3800, Australia. ${ }^{9}$ Physiotherapy, La Trobe University, Melbourne 3086, Australia.

Received: 24 January 2014 Accepted: 1 April 2014 Published: 15 April 2014 


\section{References}

1. Barker A: Bronchiectasis. N Engl J Med 2002, 346:1383-1393.

2. King $P$, Holdsworth SR, Freezer N, Villanueva E, Holmes PW:

Characteristation of the onset and presenting clinical features of adult bronchiectasis. Respir Med 2006, 100:2183-2189.

3. Martinez Garcia M, Perpina Tordera M, Roman Sanchez P, Soler Cataluna JJ: Quality of life determinants in patients with clinically stable bronchiectasis. Chest 2005, 128:739-745.

4. Olveira C, Olveira G, Gaspar I, Dorado A, Cruz I, Soriguer F, Quittner AL, Espildora F: Depression and anxiety symptoms in bronchiectasis: associations with health-related quality of life. Qual Life Res 2013, 22:597-605.

5. Chang A, Bilton D: Exacerbation in cystic fibrosis: 4-Non cystic fibrosis bronchiectasis. Thorax 2008, 63:269-276.

6. Finklea J, Khan G, Thomas S, Song J, Myers D, Arroliga AC: Predictors of mortality in hospitalised patients with acute exacerbation of bronchiectasis. Respir Med 2010, 104:816-821.

7. Martinez-Garcia M, Soler-Cataluna J, Perpina-Tordera M, Roman-Sanchez P, Soriano J: Factors associated with lung function decline in adult patients with stable non-cystic fibrosis bronchiectasis. Chest 2007, 132:1565-1572.

8. Seitz AE, Olivier KN, Adjemian J, Holland SM, Prevots R: Trends in bronchiectasis among medicare beneficiaries in the United States, 2000 to 2007. Chest 2012, 142:432-439.

9. Seitz AE, Olivier KN, Steiner CA, Montes De Oca R, Holland SM, Prevots DR Trends and burden of bronchiectasis-associated hospitalizations in the United States, 1993-2006. Chest 2010, 138:944-949.

10. Australian Institute of Health and Welfare: Asthma, chronic obstructive pulmonary disease and other respiratory diseases in Australia, 2010. [http://www.health.gov.au/internet/main/publishing.nsf/content/healthpubhlth-strateg-phys-act-guidelines]

11. Joish V, Spilsbury-Cantalupo M, Operschall E, Luong B, Boklage S: Economic burden of non-cystic fibrosis bronchiectasis in the first year after diagnosis from a US health plan perspective. Appl Health Econ Health Policy 2013, 11:299-304

12. Ringshausen FC, de Roux A, Pletz MW, Hamalainen N, Welte J, Rademacher J: Bronchiectasis-associated hospitalisation in Germany, 2005-2011 - a population-based study of disease burden and trends. PLoS One 2013, 8:e71109.

13. Pasteur M, Bilton D, Hill A, Stockley RA, Wilson R, Pasteur MC, Herriot R, Hansel DM, Bush A, Cornford C, Willcox L, Bilton D, Parry GW, Sonnappa S, Wallis C, French J, Sinfield F, Harvey A, Bott J, Pryor J, Hill AT, Greenstone M, Cunningham S, Spencer DA, Emmanue X, Kalima P, Heslop K, Elborn S, Carr S, Cole B: British Thoracic Society guidelines for non-CF bronchiectasis. Thorax 2010, 65:i1-i58.

14. Spruit MA, Singh SJ, Garvey C, ZuWallack R, Nici L, Rochester C, Hill K, Holland A, Lareau SC, Man MD, Pitta F, Sewell L, Raskin J, Bourbeau J, Crouch R, Franssen FM, Casaburi R, Vercoulen JH, Vogiatzis I, Gosselink R, Clini EM, Effing TW, Maltais F, Van Der Palen J, Troosters T, Janssen DJ, Collins E, Garcia Aymerich J, Brooks D, Fahy BF, et al: An official American thoracic society/European respiratory society statement: key concepts and advances in pulmonary rehabilitation. Am J Respir Crit Care Med 2013, 188:e13-e64.

15. Ong H, Lee A, Hill C, Holland AE, Denehy L: Effects of pulmonary rehabilitation in bronchiectasis: a retrospective study. Chron Respir Dis 2011, 8:21-30.

16. Zan Zellar M, Caetano P, Amorim A, Viana P, Martins P, Gaspar L, Hespanhol V, Gomes I: Pulmonary rehabilitation in patients with bronchiectasis: pulmonary function, arterial blood gases and the 6-minute walk test. J Cardiopulm Rehabil Prev 2012, 32:278-283.

17. Newall C, Stockley R, Hill S: Exercise training and inspiratory muscle training in patients with bronchiectasis. Thorax 2005, 60:943-948.

18. Mandal P, Sidhu M, Kope L, Pollock W, Stevenson LM, Pentland IL, Turnbul K, MacQuarrie S, Hill AT: A pilot study of pulmonary rehabilitation and chest physiotherapy versus chest physiotherapy alone in bronchiectasis. Respir Med 2012, 106:1647-1654.

19. Griffiths T, Phillips C, Davies S, Davies S, Burr ML, Campbell IA: Cost effectiveness of an outpatient multidisciplinary pulmonary rehabilitation program. Thorax 2001, 56:779-784.

20. Lee A, Cecins N, Hill C, Holland AE, Rautela L, Stirling RG, Thompson P, McDonald CF, Jenkins S: The effects of pulmonary rehabilitation in patients with non-cystic fibrosis bronchiectasis: protocol for a randomised controlled trial. BMC Pulm Med 2010, 10:1-7.
21. Mahler D, Wells C: Evaluation of clinical methods for rating dyspnea. Chest 1998, 93:580-586.

22. Global initative for chronic obstructive lung disease: Global strategy for the diagnosis, management and prevention of chronic obstructive pulmonary disease. 2013 [http://www.goldcopd.com/]

23. Global Initiative for Asthma (GINA): Global Strategy for Asthma Management and Prevention. 2012 [http://www.ginasthma.org/]

24. Pryor JA, Prasad SA: Physiotherapy problems. In Physiotherapy for Respiratory and Cardiac problems. Edited by Pryor JA, Prasad S. United Kingdom: Elsevier; 2008:398-394.

25. Alison J, Barrack C, Cafarella P, Frith P, Hanna C, Hill CJ, Holland AE, Jenkins S, Meinhardt J, McDonald CF, McKeough Z, Patman S, Ross J, Seale H, Shoemaker C, Spencer L, Allan H, Banks S, Barrett S, Beeley H, Blake J, Boden I, Cecins N Cockram J, Herd K, Hill K, Langdon C, Lee AL, Leung R, McNamara R, et al: Pulmonary rehabilitation toolkit. [www.pulmonaryrehab.com.au]

26. Nici L, Donner C, Wouters E, Zuwallack R, Ambrosino N, Bourbeau J, Carone M, Celli B, Engelen M, Fahy B, Garvey C, Goldstein R, Gosselink R, Lareau S, Maclntye N, Maltais F, Morgan M, O'Donnell D, Prefault C, Reardon J, Rochester C, Schols A, Singh S, Troosters T, on behalf of the ATS/ERS Pulmonary rehabilitation writing committee: American Thoracic Society/ European Respiratory Society statement on pulmonary rehabilitation. Am J Respir Crit Care Med 2006, 173:1390-1413.

27. Hill K, Jenkins SC, Cecins N, Philippe DL, Hillman DR, Eastwood PR: Estimating maximal work rate during incremental cycle ergometry testing from six-minute walk distance in patients with chronic obstructive pulmonary disease. Arch Phys Med Rehabil 2008, 89:1782-1787.

28. Holland A, Hill C, Conron M, Munro P, McDonald CF: Short term improvement in exercise capacity and symptoms following exercise training in interstitial lung disease. Thorax 2008, 63:549-554

29. Australian Government, Department of Health: Physical Activity guidelines. 2013 [http://www.health.gov.au/internet/main/publishing.nsf/content/ health-pubhlth-strateg-phys-act-quidelines\#quidelines_adults]

30. Singh S, Morgan M, Scott S, Walters D, Hardman AE: Development of a shuttle walking test of disability in patients with chronic airway obstruction. Thorax 1992, 47:1019-1024

31. Williams J, Singh S, Sewell L, Guyatt GH, Morgan MD: Development of a selfreported Chronic Respiratory Questionnaire (CRQ-SR). Thorax 2001, 56:954-959.

32. American Thoracic Society: Guidelines for the 6-minute walk test. Am J Respir Crit Care Med 2002, 166:111-117.

33. Murray M, Turnbull K, MacQuarrie S, Pentland JL, Hill AT: Validation of the Leicester Cough Questionnaire in non-cystic fibrosis bronchiectasis. Eur Respir J 2009, 34:125-131.

34. Zigmond A, Snaith R: The hospital anxiety and depression scale. Acta Pyschiatr Scand 1983, 67:361-370.

35. Hawthorn G, Osborne R: Population norms and meaningful differences for the Assessment of Quality of Life (AQOL) measures. Aust NZ J Public Health 2005, 29:136-142.

36. Lachin JM: Statistical considerations in the intent-to-treat principle. Control Clin Trials 2000, 21:167-189.

37. Miller ME, Morgan TM, Espeland MA, Emerson SS: Group comparisons involving missing data in clinical trials: a comparison of estimates and power (size) for some simple approaches. Stat Med 2001, 20:2383-2397.

38. Schultz KF, Altman DG, Moher D, the CONSORT Group: CONSORT 2010 Statement: updated guidelines for reporting parallel group randomised trials. BMC Med 2010, 8:18.

39. Santamato A, Ranieri M, Panza F, Frisardi V, Marvulli R, Filoni S, Cisari C, Fiore $P$ : Pulmonary rehabilitation for patients with bronchiectasis: case reports. Eur J Phys Rehabil Med 2012, 48:293-298.

40. Akimoto T, Kumai Y, Hayashi E, Hayashi E, Murakami H, Soma R, Kuno S, Kono I: Effects of 12 months of exercise training on salivary secretory lgA levels in elderly subjects. Brit J Sports Med 2003, 37:76-79.

41. Dwyer T, Alison J, McKeough ZJ, Daviskas E, Bye PT: Effects of exercise on respiratory flow and sputum properties in patients with cystic fibrosis. Chest 2011, 139:870-877.

42. Angrill J, Agusti C, de Celis R, Rano A, Gonzalez J, Sole T, Xaubet A Rodriguez-Roison $\mathrm{R}$, Torres A: Bacterial colonisation in patients with bronchiectasis: microbiological pattern and risk factors. Thorax 2002, 57:15-19.

43. Loebinger MR, Wells AU, Hansell DM, Chinyanganya N, Devaraj A, Meister M, Wilson R: Mortality in bronchiectasis: a long-term study assessing the factors influencing survival. Eur Respir J 2009, 34:843-849. 
44. Puhan M, Chandra D, Mosenifar Z, Ries A, Make B, Hansel NN, Wise RA, Sciurba F: The minimal important difference of exercise tests in severe COPD. Eur Respir J 2011, 37:784-790.

45. King PT, Holdsworth SR, Freezer NJ, Vallanueva E, Farmer MW, Guy P, Holmes PW: Lung diffusing capacity in adult bronchiectasis: a longitudinal study. Respir Care 2010, 55:1686-1692.

46. King PT, Holdsworth SR, Freezer NJ, Villanueva E, Gallaher M, Holmes PW: Outcome in adult bronchiectasis. Int I of Chron Obstruct Pulmon Dis 2005, 2:27-34

47. Tantucci C, Modina D: Lung function decline in COPD. Int I of Chron Obstruct Pulmon Dis 2012, 7:95-99.

48. Ley B, Collard HR, King TE Jr: Clinical course and prediction of survival in idiopathic pulmonary fibrosis. Am J Resp Crit Care Med 2011, 183:431-440.

49. Beauchamp M, Janaudis-Ferreira T, Goldstein R, Brooks D: Optimal duration of pulmonary rehabilitation for individuals with COPD - a systematic review. Chron Respir Dis 2011, 8:129-140.

50. Pitta F, Troosters T, Probst V, Langer D, Decramer M, Gosselink R: Are patients with COPD more active after PR. Chest 2008, 134:273-280.

51. Wempe J, Wijkstra P: The influence of rehabilitation on behaviour modification in COPD. Patient Educ Couns 2004, 52:237-241.

doi:10.1186/1465-9921-15-44

Cite this article as: Lee et al.: The short and long term effects of exercise training in non-cystic fibrosis bronchiectasis - a randomised controlled trial. Respiratory Research 2014 15:44.

\section{Submit your next manuscript to BioMed Central and take full advantage of:}

- Convenient online submission

- Thorough peer review

- No space constraints or color figure charges

- Immediate publication on acceptance

- Inclusion in PubMed, CAS, Scopus and Google Scholar

- Research which is freely available for redistribution 